\title{
O ENSINO DOS JESUÍTAS NA UNIVERSIDADE DE ÉVORA - O USO DIDÁTICO DE AZULEJOS NO COLÉGIO DO ESPÍRITO SANTO
}

Francisco António Lourenço Vaz ${ }^{1}$

\section{RESUMO}

Neste trabalho descrevemos as fases do revestimento das salas de aula do Colégio do Espírito Santo com azulejos e estabelecemos a relação entre os painéis e o ensino ministrado. Num ambiente pedagógico em que a imagem era rara nos manuais, os painéis vinham dar uma nova dimensão ao ensino, motivavam os alunos e complementavam a aprendizagem dos conteúdos. Como fontes usamos os azulejos das salas de aula da Universidade, os manuais utilizados no ensino e descrições feitas sobre o colégio.

Palavras-chave: jesuítas, ensino universitário, painéis de azulejos, imagens.

${ }^{1}$ Universidade de Évora, Évora, Portugal. 


\title{
LA ENSEÑANZA DE LOS JESUITAS EN LA UNIVERSIDAD DE ÉVORA - EL USO DIDÁCTICO DE AZULEJOS EN EL COLEGIO DEL ESPÍRITU SANTO
}

\section{RESUMEN}

En este trabajo, describimos las fases del revestimiento de las aulas del Colegio do Espirito Santo con azulejos y establecemos la relación entre los paneles y la enseñanza. En un entorno pedagógico en que la imagen era rara en los manuales, los paneles agregaron una nueva dimensión a la enseñanza, motivaron los estudiantes y complementaron el aprendizaje de contenidos. Como fuentes utilizamos los mosaicos de las aulas de la universidad, los manuales de la enseñanza y descripciones del colegio.

Palabras clave: jesuitas, enseñanza universitaria, paneles de azulejos, imágenes.

\section{THE TEACHING OF THE JESUITS AT THE UNIVERSITY OF ÉVORA - THE DIDACTIC USE OF TILES AT THE COLLEGE OF THE HOLY SPIRIT}

\begin{abstract}
In this work, we describe the phases of covering the classrooms of Colégio do Espirito Santo with tiles and establish the relationship between the panels and the teaching. In a pedagogical environment in which the image was rare in the manuals, the panels added a new dimension to teaching, motivated students and complemented the learning of the contents. As sources we use the tiles of the University classrooms, the manuals used in teaching and descriptions made about the college.
\end{abstract}

Keywords: jesuits, university teaching, tiles, images.

\section{L'ENSEIGNEMENT JESUITE A L'UNIVERSITE D'ÉVORA - UTILISATION DIDACTIQUE DES CARREAUX AU COLLEGE DU SAINT-ESPRIT}

\section{RÉSUMÉ}

Dans ce travail, nous décrivons les phases du revêtement des salles de classe du Colégio do Espirito Santo avec des tuiles et établissons la relation entre les panneaux et l'enseignement. Dans un environnement pédagogique où l'image était rare, les panneaux ont ajouté une nouvelle dimension à l'enseignement, motivé les étudiants et complété l'apprentissage. Comme sources, nous utilisons les tuiles des salles de l'Université, les manuels de l'enseignement et les descriptions faites sur le collège.

Mots-clés: jésuites, enseignement universitaire, tuiles, images. 


\section{INTRODUÇÃO}

Poucos anos antes da extinção da Universidade de Évora, determinado pelo Marquês de Pombal em 1759, as aulas do Colégio Espírito Santo foram revestidas com azulejos, obra concluída em 1749, ou seja, 10 anos antes da extinção. Esta pode ter sido a última reforma pedagógica dos jesuítas na Universidade de Évora. Como têm sublinhado alguns estudos, o uso de azulejos, para reforçar ou ilustrar os ensinos ministrados, foi resultado das determinações do Ratio Studiorum e, no caso do ensino da Matemática, era prática estabelecida nas casas dos jesuítas, desde 1735, nomeadamente, no Colégio de Santo Antão em Lisboa e no Colégio das Artes em C oimbra (LEITÃO, 2007a). Deve ter sido na sequência dessa renovação que se pensou e executou o projeto na Universidade de Évora. Projeto audacioso, que ainda hoje constitui um dos motivos de maior interesse da Universidade, dado o valor patrimonial e pelo sentido estético que as imagens proporcionam.

Rómulo de Carvalho sublinhou uma nova atitude pedagógica da Companhia de Jesus: "uma consciência que nunca se impusera com tanta convicção: a da importância social da educação e do ensino" (CARVALHO, 2008, p. 329). Outros estudos recentes têm apontado a inovação e modernidade do ensino dos jesuítas, o carácter gradual do ensino, a utilização dos alunos mais adiantados, os decuriões (MONTEIRO, 2009, 2011) e o avanço do ensino da Matemática nos colégios da Companhia (LEITÃO, 2003; 2007b). Relativamente às disciplinas e seus planos de estudo, é de salientar a obra de Pereira Gomes (1960), com notícia do ensino dos mestres jesuítas no curso de Filosofia, desde a fundação da universidade até ao seu encerramento em 1759, transcrevendo os tópicos das conclusões, ou como diríamos hoje as teses, defendidas por alunos nos atos públicos. Neste domínio considera que, no século XVIII, os mestres jesuítas teriam esquecido as determinações estatutárias e que nos seus cursos já defendiam as novas ideias científicas, no caso da Física e da própria Filosofia Racional (GOMES, 1960). Do mesmo modo, Fonseca (2011), num estudo sobre a fundação e os primeiros 200 anos da 
Universidade, descreve a evolução do ensino dos jesuítas, com dados estatísticos sobre o número de matriculados e graduados, comprovando que no século XVIII o ensino teve um desenvolvimento, quer em termos de métodos, quer em aumento de graduados. No mesmo sentido, Amélia Polónia, que considera que a fundação da Universidade de Évora resultou de um projeto pastoral e pedagógico, tem referenciado a inovação e modernidade pedagógica e científica do ensino dos jesuítas nos primeiros anos do seu funcionamento (POLÓNIA, 2012). No domínio da Retórica, Ana Miranda, utilizando as normas estabelecidas na Ratio Studiorum (1599) e o manual utilizado nas aulas dos jesuítas, a obra de Cipriano Soares, De Arte Rethorica libri tres (1562), sublinha o valor instrumental desta "arte de persuasão" e importância que assumia no contexto da missão social dos jesuítas (MIRANDA, 2016).

Relativamente ao ensino dos jesuítas na Universidade de Évora, são ainda de referir os estudos de Francisco Vaz, que tomou por base o testemunho de alunos que frequentaram e se formaram na Universidade, casos de Severim de Faria, Luís António Verney e Bento Farinha (VAZ, 1998; 2012), bem como os Estatutos que, desde o século XVI, regiam os estudos (VAZ, 2016).

Sobre a temática dos azulejos do Colégio do Espírito Santo foram publicados alguns estudos. Entre eles destaca-se o de Mendeiros (2002), um catálogo completo sobre os painéis, com a menção das máximas latinas e nomes, bem como uma pequena descrição das cenas representadas. As obras de Simões $(1971$; 1990; 1997) constituem uma referência para a arte e estética do azulejo em Portugal, do século XV ao XVIII. O autor, que foi também o primeiro diretor do Museu do Azulejo, fez um inventário da azulejaria em Portugal. Relativamente ao Colégio do Espírito Santo, a descrição dos azulejos da sala dos atos e das salas de aula feita por Simões segue aquele critério de inventário, com poucas referências ou relação com o ensino ministrado. Maria Pereira (2012, p. 657) refere a importância científica das imagens, particularmente as experiências representadas nos azulejos das aulas de Física e Geometria, considerando que documentam que os mestres jesuítas tinham conhecimento 
da física moderna e da filosofia de Descartes, o que, segundo a mesma autora, refuta o argumento da decadência do ensino, invocado em 1759 para o fecho da universidade. De facto, como outros estudos têm sublinhado, o governo pombalino invocou a decadência do ensino como argumento para a centralização politica no contexto do absolutismo esclarecido (CARVALHO, 2008; VAZ, 2016).

Estabelecendo uma relação entre as imagens e o ensino ministrado, Ferreira Patrício (2012, p. 77) considera que as imagens dos azulejos representam uma inovação pedagógica, pois ilustravam as várias temáticas do ensino ministrado na universidade.

Relacionado com a nossa temática é o estudo de Tobias (1987), centrado na questão da definição das ciências e na importância do valor documental dos azulejos, em especial para o ensino científico no contexto do século XVIII. Faltalhe, todavia, uma relação mais fina com o ensino ministrado pelos jesuítas que permita aferir a utilização pedagógica das imagens e máximas.

Coligindo vários textos, da historiografia e das fontes primárias existentes, entre as quais as mais elucidativas são os próprios azulejos, colocados há mais de 250 anos e que ainda hoje temos nas salas e corredores do Colégio, é possível traçar a evolução do revestimento de diferentes partes do edifício com silhares de azulejo policromados.

\section{O REVESTIMENTO COM AZULEJOS}

O revestimento com azulejos, de diversas dependências do Colégio do Espirito Santo, foi um projeto lento e que teve início ainda no tempo do Cardeal D. Henrique, com a colocação de azulejos nas duas capelas, obra concluída em 1568 (CONDE, 2012). Já na centúria seguinte, em 1620, foram colocados os azulejos na sala de atos. Nos primeiros tempos da universidade, a atual sala dos atos era a igreja da comunidade e manteria essa função até ao ano de 1574, 
quando se concluiu a atual igreja do Espírito Santo, anexa ao edifício do colégio (LOBO, 2009, p. 42-43). Em 1631, foi a vez de revestir a capela-mor da Igreja do Espírito Santo, com azulejos policromados e em 1700 acrescentaram-se os azulejos azuis e brancos. Em 1701 colocaram-se os azulejos na casa da portaria. Entre 1723 e 1725, fez-se a colocação de azulejo na botica e um painel sobre a porta. São também de assinalar os melhoramentos feitos, entre 1734 e 1737, a execução das portas das salas de aula em pau-brasil e de novas cátedras sobre pedestais de mármore, obras que precederam a colocação dos azulejos nas salas de aula (BRANCO, 2005, p. 5).

Até ao presente não se encontrou uma fonte documental completa que descreva a colocação dos silhares de azulejos nas salas de aula. Uma das referências que tem sido citada em alguns estudos e que, embora não estando datada, se atribui ao tempo em que se procedeu à colocação de azulejos nas salas, é um memorial do P. Vicente Lopes, que foi Reitor no Colégio e na passagem de testemunho ao seu sucessor, o Padre José de Andrade, refere que algumas das salas já estão revestidas a azulejo - a de Teologia e cinco salas de aulas de latim e humanidades - e que já estavam encomendados azulejos em Lisboa para mais duas salas. Merece ser citada a referida passagem:

No Pátio da Universidade se fez a cadeira de Teologia, e se fizeram de novo na forma, que hoje estão, a 3.a classe, a 7.a a 8.a e a 5.a e 4. curso tudo à custa da Arca da Universidade e da Imprensa por devoção do P. Secretário José de Andrade, que já tem as pedras para as duas classes, que lhe faltam, e encomendado em Lisboa o azulejo ${ }^{2}$ ( LOPES, Vicente apud TOBIAS, 1987, p. 25).

A passagem interessa, particularmente, para comprovar que os azulejos foram fabricados em Lisboa e que a obra correu a expensas da Universidade, com recurso às receitas do orçamento e da tipografia universitária, que era desde o século XVI uma das principais inovações ao serviço do ensino e divulgação das obras dos mestres jesuítas.

${ }^{2}$ Atualizámos a ortografia. 
Tudo faz crer que foi na década de quarenta do século XVIII, que se procedeu a feitura de azulejos para a maioria das salas de aula, obra que terá sido concluída, com a execução dos azulejos do noviciado, colocação de azulejo proveniente de Lisboa, na sala de aula de Teologia (1747), e finalmente com o revestimento da sala José do Egipto, com painéis alusivos a vida deste patriarca. Esta cronologia toma em consideração as referências que estão assinaladas nos próprios painéis de azulejos: na sala 123, a designada casa do perfeito de estudos e matrícula, está a data 1746, na sala 122 está a data 1747 e na sala José do Egito num dos painéis está a data 1749.

Partindo de anteriores análises, sobre plano de estudos que os jesuítas seguiam em Évora em meados do século XVIII (VAZ, 2016), procuremos estabelecer as relações entre o ensino ministrado e os painéis de azulejos das salas de aula.

\section{A DIDÁTICA DOS AZULEJOS}

De acordo com testemunhos do século XVIII, o ensino elementar era ministrado "fora de portas", ou seja, no recinto exterior ao designado Pátio de Estudos, para não misturar as crianças com os alunos mais velhos. No Pátio de Estudos, os Gerais da Universidade, funcionavam oito classes: o ensino do Latim, que era dado em quatro classes, a Retórica, dada em duas e as Humanidades, também em duas33. Após o Latim e a Retórica, os estudantes seguiam o Curso de Artes, a Filosofia, dado em quatro anos, incluindo as conclusões para os exames de bacharéis e licenciados, que ocupavam o último semestre e, portanto, as aulas terminavam no fim do primeiro semestre do terceiro ano. O Curso de Teologia durava cinco anos, mas só os três primeiros

\footnotetext{
3 A partir de 1599 e de acordo com a Ratio Studiorum as oito classes, previstas nos estatutos, foram assim distribuídas, a começar com o nível mais elevado até ao primeiro nível da gramática latina: "de modo que a primeira e segunda formassem a de retórica; a terceira e quarta a de humanidade; a quinta e sexta respetivamente a de gramática suprema e a de média; e a sétima e oitava a de ínfima gramática” (RODRIGUES, v. 2, 1938, p. 25).
} 
eram dedicados a aulas, já que os últimos dois anos eram para preparar as conclusões a defender e fazer os exames e atos públicos.

Outro dado a ter em consideração é que só funcionavam aulas nos Gerais, ou Pátio de Estudos, pois nas dependências do piso superior do Colégio estavam os dormitórios, livraria, cartório, capela da comunidade, cubículos dos lentes e outras dependências. A nível do claustro principal estavam os dois claustros mais pequenos: o dos irmãos e o da botica, bem como o refeitório e a cozinha. Temos assim um total de 13 salas de aula, mais duas salas reservadas para os atos públicos - a sala de atos para licenciados, que inicialmente era a igreja, e sala de atos para bacharéis e mestres de Artes, fora dos Pátio de Estudos, onde funcionava também o Senado Universitário e que hoje é designada sala José do Egito.

Faz sentido que o Latim, as Humanidades e Retórica ocupem oito salas, dado que o seu ensino era imprescindível para o prosseguimento dos estudos e provavelmente as classes ocupavam salas diferentes. Neste ciclo de estudos incluímos duas salas para a Retórica, a 118, dita aula da Eneida, epopeia de referência na arte de persuasão e a designada Aula de Geografia (122), porque esta disciplina, tal como a História, era subsidiária da Retórica (RUEGG, 2002). No Quadro 1 seguinte apresentamos a lista das salas e manuais para este ciclo de estudos.

Quadro 1 - Latim, Retórica e Humanidades.

\begin{tabular}{|l|l|l|l|}
\hline \multicolumn{1}{|c|}{ SALAS } & \multicolumn{1}{|c|}{ AULAS/ TEMAS } & PAINÉIS DE AZULEJOS & MANUAIS \\
\hline 103 & $\begin{array}{l}\text { Gramática Latina: } \\
\text { Nominativos e Rudimentos }\end{array}$ & $\begin{array}{l}\text { Cenas de pesca, caça e } \\
\text { campestres }\end{array}$ & $\begin{array}{l}\text { P. Manuel } \\
\text { Alvares (SJ): } \\
\text { Gramática }\end{array}$ \\
\hline 104 & $\begin{array}{l}\text { Gramática Latina: Géneros } \\
\text { e Pretéritos }\end{array}$ & Cenas de pesca e caça & Idem \\
\hline 105 & Gramatica latina: Sintaxe & Cenas de caça & Idem \\
\hline
\end{tabular}




\begin{tabular}{|l|l|l|l|}
\hline \multicolumn{1}{|c|}{ SALAS } & \multicolumn{1}{|c|}{ AULAS/ TEMAS } & PAINÉIS DE AZULEJOS & \multicolumn{1}{|c|}{ MANUAIS } \\
\hline 106 & Gramatica latina: Sintaxe & $\begin{array}{l}\text { Representação dos meses do } \\
\text { ano e signos do zodíaco }\end{array}$ & Idem \\
\hline 107 & $\begin{array}{l}\text { Humanidades: Construção } \\
\text { de Ovídeo e Virgílio }\end{array}$ & Géneros literários & $\begin{array}{l}\text { Obras de Ovídio } \\
\text { e Virgílio. }\end{array}$ \\
\hline 110 & $\begin{array}{l}\text { Humanidades: Construção } \\
\text { de Ovídeo e Virgílio }\end{array}$ & Cenas bucólicas & $\begin{array}{l}\text { Obras de Ovídio } \\
\text { e Virgílio. }\end{array}$ \\
\hline 118 & $\begin{array}{l}\text { Construção e rudimentos } \\
\text { de Retórica }\end{array}$ & Cenas da Eneida & $\begin{array}{l}\text { Cipriano Soares } \\
\text { (SJ) De arte } \\
\text { Rhetorica }\end{array}$ \\
\hline 122 & $\begin{array}{l}\text { Construção e rudimentos } \\
\text { de Retórica Geografia }\end{array}$ & $\begin{array}{l}\text { Representação continentes. } \\
\text { Estações do ano e os quatro } \\
\text { elementos. }\end{array}$ & $\begin{array}{l}\text { Cipriano Soares } \\
\text { De arte } \\
\text { Rhetorica }\end{array}$ \\
\hline
\end{tabular}

Fonte: Mendeiros, 2002; Vaz, 2016.

Restam portanto cinco aulas, reservadas para o curso de Artes e para a Teologia. Para as Artes, a Filosofia, seriam atribuídas a aula de Geometria (114), cujo ensino era considerado necessário como propedêutico para a Física; a de Filosofia (119), a de Física (120) e a de Metafisica (121). Para a Teologia, lecionada por dois Lentes de manhã e outros dois de tarde4, era atribuída uma das salas mais espaçosa, que ladeava a primitiva igreja e depois sala dos atos, a sala da Escritura Sagrada (115). Esta atribuição está de acordo com a mentalidade pedagógica da época, que encarava a Teologia como a "Ciência Maior” e que como tal deveria ter uma proeminência mesmo a nível de representação no espaço ocupado. Como é sabido, nas sociedades de antigo regime o lugar de proeminência, a nível social ou religioso, era norma nas representações públicas; veja-se a hierarquia que era estabelecida, relativamente aos lugares dos diferentes grupos sociais, nos rituais públicos como missas, procissões e autos-de-fé. No Quadro 2 seguinte resumimos a

\footnotetext{
4 Este número toma em consideração os estatutos: "A lição de prima de teologia, durará hora e meia, e a de véspera e de escritura, uma hora, a de casos, pela manhã, uma hora, e também a da tarde outra hora". Estatutos da Universidade de Évora (1580) (VAZ; PEREIRA, 2012b, p. $59)$.
} 
afetação das salas para estes cursos.

Quadro 2 - Cursos de Artes e Teologia.

\begin{tabular}{|c|c|c|c|}
\hline SALAS & AULAS/ TEMAS & PAINÉIS DE AZULEJOS & MANUAIS \\
\hline 114 & $\begin{array}{l}\text { Geometria e } \\
\text { Astronomia }\end{array}$ & $\begin{array}{l}\text { Cenas de Astronomia, } \\
\text { Geometria, Balística e } \\
\text { artilharia }\end{array}$ & $\begin{array}{l}\text { Tacquet (SJ) - } \\
\text { Elementos de Euclides }\end{array}$ \\
\hline 119 & Lógica & Cenas de filósofos gregos & $\begin{array}{l}\text { P. Silvestre Aranha } \\
\text { (S.J), Disputationes } \\
\text { Logica }\end{array}$ \\
\hline 120 & Física & Experiências físicas & $\begin{array}{l}\text { P. António Mayr (SJ), } \\
\text { Philosophia } \\
\text { peripatética. Physica } \\
\text { Universalis (1745) }\end{array}$ \\
\hline 121 & Metafisica & Temas da Metafisica & $\begin{array}{l}\text { Aristóteles, Parva } \\
\text { Naturalia }\end{array}$ \\
\hline 115 & $\begin{array}{l}\text { Teologia S. Tomás } \\
\text { Casos e Escritura } \\
\text { Sagrada }\end{array}$ & Cenas Bíblicas & $\begin{array}{l}\text { Bíblia } \\
\text { Obras de S, Tomás } \\
\text { Suma } \\
\text { Caietana }\end{array}$ \\
\hline 123 & Matricula & Cenas de caça e pesca. & - \\
\hline 124 & $\begin{array}{l}\text { Conselho } \\
\text { Universitário Atos e } \\
\text { exames de } \\
\text { bacharéis e mestres } \\
\text { de Artes. }\end{array}$ & $\begin{array}{l}\text { Vida de José do Egipto. } \\
\text { Indicação data } 1749 .\end{array}$ & - \\
\hline 112 & $\begin{array}{l}\text { Atos de Licenciados } \\
\text { em Artes }\end{array}$ & Motivos florais & - \\
\hline
\end{tabular}

Fonte: Mendeiros, 2002; Vaz, 2016.

Importa, portanto, procurar a relação entre os temas abordados nas diferentes disciplinas, com os manuais adotados e os painéis de azulejos de cada uma das salas. 


\section{OS MANUAIS DE ENSINO}

No que respeita aos manuais, constata-se o predomínio das obras de autores da Companhia, comprovando o argumento dos críticos que apontavam este "preconceito de escola", como um dos pontos para os jesuítas não aceitarem as inovações pedagógicas vindas de outros quadrantes. Foi nesse sentido que Luís Vernei considerou que o ensino do Latim tinha estagnado nas casas dos jesuítas, porque persistiam em usar "o seu Manuel Alvares".

A obra de Manuel Alvares, De Instructione Grammatica Libri tres, é provavelmente uma das obras dos jesuítas com mais edições, quer em Portugal quer no estrangeiro5. Consultámos uma edição publicada em 1689, na tipografia da Universidade de Évora. A gramática propriamente dita tem 331 páginas, sem qualquer imagem, agrupando a matéria em três livros. O primeiro é dedicado aos nomes (substantivos, adjetivos e advérbios), aos verbos (as diversas conjugações) e aos rudimentos para construção de frases; o segundo à sintaxe e à construção da frase De octo Partibus Orationes (173) e o terceiro dedicado às sílabas, nos nomes e verbos, versos, patronímicos e prosódia: De Gramatica Instituitiones (255). A obra inclui um índice alfabético (p. 332-566), com tradução para Português das palavras latinas utilizadas na gramática, com indicação da página onde foram utilizadas, instrumento pedagógico fundamental para os principiantes e que muito terá contribuído para o seu sucesso e longevidade no ensino dos jesuítas.

Nas aulas de Retórica, o manual adotado pelos jesuítas era a De arte rhetorica libri tres ex Aristotele, obra de Cipriano Soares, também padre jesuíta, que logo no primeiro livro, aponta trechos de Cícero e de Virgílio (Eneida) como exercícios e no terceiro livro, no início do primeiro capítulo, tem a capitular P, com uma gravura e com figuras do que parece ser Jesus Cristo, uma mulher ajoelhada, um homem de pé ao lado da mulher e um cavaleiro

\footnotetext{
5 Segundo Cardoso (1995, p. 159): "530 edições em 22 países, incluindo o México, a China e o Japão, fora da Europa [...]. Na Itália contaram-se mais de 100 edições, na Bélgica, 73, na Checoslováquia, 71, Polónia com igual número e em Portugal 25”.
} 
apeado, mas com o cavalo ao lado e próximo da figura central. Também neste capítulo cita nas margens Cícero e Quintiliano. Faz, portanto, sentido que a sala utilizada para o ensino da Retórica seja revestida com azulejos alusivos à Eneida de Virgílio, a sala 118.

No curso de Artes, a Filosofia, em meados do século XVIII, o manual era obra de António Mayer, também padre jesuíta, intitulada Philosophia peripatetica: antiquorum principiis et recentiorum experimentis conformata (1745) que se divide em quatro tomos, sendo o primeiro dedicado à Lógica, o segundo à Física, o terceiro à Metafisica e o quarto à Matemática. Porque, como se indica no primeiro tomo, as ciências primárias são essas: Lógica, Física, Metafisica e Matemática (MAYER, 1745, v. 1, p. 502). Logo no primeiro tomo, dedicado à Lógica, na carta ao leitor, o P. Mayer presta o seu tributo a Aristóteles o Estagirita, o criador da filosofia peripatética, e cujas máximas considera válidas, apesar dos comentários ou acrescentos dos autores mais recentes, como Descartes, que refere, ou mesmo mais antigos como Epicuro e Empédocles. Este tributo continua ao longo do texto do manual, com referências elogiosas a Aristóteles visto como magnus Philosophus.

O segundo tomo da monumental obra do P. Mayer (1745) era recomendado na Universidade de Évora para o ensino da Física. Qualquer leitor atual constata a aridez do manual na exposição da matéria, sobretudo pela grande extensão do livro, com 770 páginas, e pela quase ausência de imagem, apenas algumas capitulares apresentam febos, anjos e motivos florais. A matéria é exposta de acordo com o método peripatético da disputationum, quaestionum e articulorum; ou como diríamos do debate, questões e princípios. Desmonta o sistema filosófico cartesiano, o cogito ergo sum; revelando conhecimento de Descartes, da obra As Meditações, e seguindo na refutação desse sistema a obra de lógica de outro autor jesuíta Renatus Rapinus (1621-1687) (MAYER, 1745, t. 2, p. 151-156). A autoridade é Aristóteles mas secundada pela própria Escritura Sagrada, que por diversas vezes o autor invoca. Por exemplo, ao tratar a Quaestio V- De Proprietatibus Materiae Prima, em 6 artigos, refere o sistema 
aristotélico, sobre essência e existência, e cita a Bíblia, Exodo: Ego sum, qui sum, para comprovar que só Deus tem identificadas a essência e a existência (MAYER, 1745, t. 2, p. 164-204). Do mesmo modo ao tratar a Disputatio II - De Natura e Arte; onde começa por considerar que a arte é semelhante à natureza, símia da natureza, ou imita a natureza, mas é também émula da natureza. Discorre depois sobre o tema em cinco artigos: o que é a natura, o que seja natural e sobrenatural, o que é neutro e o que é violento (MAYER, 1745, t. 2, p. 331-352). Sobre o que é natureza, discorre sobre os princípios Natura Naturans e Natura Naturata, seguindo a Física de Aristóteles (idem, p. 332) mas secundado o mestre com a Bíblia, livro de Levítico, 20, v. 9, e outros autores: Arriaga (idem, p. 332-333) e Suarez (idem, p. 334).

Os painéis das salas onde era ministrado o ensino da Filosofia, que incluía a Física, comprovam também que Aristóteles era a principal referência desse ensino. Com efeito, o Estagirita é o autor mais representado, surge mencionado e representado em 4 painéis na sala 119 e em 3 na 120 . Na sala 119 os painéis representam respetivamente: Platão ensinando Aristóteles nos jardins do Acádemo em Atenas, Aristóteles ensina o jovem Alexandre, Aristóteles ensinando os discípulos no Liceu e Aristóteles na Academia de Platão. Na sala 120 Aristóteles surge ensinando aos discípulos deambulando entre arcadas, ensinando o uso do pó simpático (para curar doenças) e ensinando as experiencias do magnetismo com anéis e limalhas.

Para a Metafisica, o manual utilizado na Universidade jesuítica era a Parva Naturalia de Aristóteles, obra que incluía sete obras sobre a Natureza, o corpo e a alma: da sensação e do sensível; da memória e reminiscência; do sono e da vigília; dos sonhos; da adivinhação pelo sonho; da longevidade e brevidade da vida; da juventude e da velhice, da vida e da morte, da respiração. Os painéis de azulejos da sala 121 constituem um bom complemento para o ensino metafísico, dado que apresentam diversas personificações da metafísica, representada por máquinas de tecelagem, por aves, ou fábricas de essências e perfumes, com máximas instrutivas e apropriadas ao ensino metafísico, como a 
que alude a Deus: Motor motu et mobila (O motor que move todas as coisas) e outra que indica a finalidade do ensino metafisico: Quarit rerum essentias (investiga as essências das coisas).

\section{UMA BANDA DESENHADA EM AZULEJOS}

O uso de imagens no ensino era já uma tradição dos jesuítas, a começar no ensino mais elementar, o do catecismo, no qual usavam, desde o século XVI, a Doutrina Cristã do P. Marcos Jorge (1566), posteriormente reeditada com acrescentos, pelo P. Inácio Martins e que seria uma obra dos jesuítas com numerosas edições e traduções (VAZ, 2017). Se na primeira edição de 1566 este catecismo não tinha imagens na de 1599, já com os acrescentos feitos por Mestre Inácio, apresentava 21 imagens alusivas aos principais momentos da vida de Cristo e de Nossa Senhora, grande parte delas colocadas no tratado "modo de rezar o rosário", e que davam aos crentes a possibilidade completar os conhecimentos evangélicos:

Para os mistérios gozosos, são representadas: anunciação, visitação, oferecimento, nascimento de Cristo, apresentação no templo e Jesus entre os doutores. Para os dolorosos: agonia de Jesus no horto, flagelação, coroação de espinhos, Jesus transportando a cruz, crucificação. Para os gloriosos: ressurreição, ascensão, vinda do Espírito Santo, assunção de Nossa Senhora, coroação de Nossa Senhora (VAZ, 2017, p. 32).

Em 1616 seria feita uma edição de luxo da Doutrina Cristã, em Ausburgo, profusamente ilustrada. No prefácio a essa edição o padre jesuíta Jorge Mayr dá um argumento que nos mostra o valor didático que então era atribuído às imagens no ensino. Recorrendo à autoridade de São Gregório, segundo ele a grande vantagem das imagens no catecismo, é a possibilidade que dão para instruir os iletrados: "o que os doutos leem na escritura acham os idiotas na pintura" (SANTOS, 2016, p. 23). Se tivermos presente o contexto 
cultural da época moderna, em que nos países católicos os crentes não podiam ler a Bíblia na sua língua, estas imagens nos catecismos permitiam-lhe uma descrição, ainda que padronizada, da mensagem evangélica e como tal adquiriam um papel fundamental no ensino catequético e missionação. Era portanto um dado adquirido que as representações de cenas da vida de Cristo e da Virgem tinham um valor pedagógico que, não só colmatava a falta de literacia da grande maioria da população, como também completava o discurso simples dos catecismos, reforçando a mensagem com imagens.

No que respeita ao ensino nos Colégios dos Jesuítas, Henrique Leitão analisou a importância das imagens dos azulejos no ensino da Matemática, no Colégio de Santo Antão, e considera que o revestimento de salas de aula nos colégios dos jesuítas está associado ao movimento de renovação científica iniciado, com a Ordinatio de Tirso González de 1692 que tinha por objetivo melhorar o ensino da matemática com a utilização das imagens:

Este quinto ponto da Ordinatio dá ainda indicações sobre o material que cada aluno deveria possuir: uma régua e um compasso, e, seguidamente, apresenta a indicação que explica o aparecimento dos azulejos: no local onde se dá a aula de matemática deve haver um quadro amplo, com as figuras correspondentes às principais demonstrações (LEITÃO, 2007a, p. 26).

É neste contexto de renovação científica que devemos também incluir o revestimento das salas de aula do Colégio do Espirito Santo, com azulejos alusivos aos temas lecionados.

Na sala de aula da Universidade dos jesuítas, a cátedra era o elemento básico fundamental, o centro do ensino ministrado. Era na cátedra que se sentava o mestre para "ler a lição", tal como estipulava o princípio do magister dixit. De acordo com arquitetura e arrumação do espaço, os alunos seguiam a preleção do mestre, sentados nos bancos corridos (4), adossados às paredes e suportados por pilares de mármore. Por isso, o local com mais visibilidade era a cátedra, como era de exigir, para ver o Mestre no seu lugar proeminente. 
Esta disposição do espaço da aula condiciona, de algum modo, um uso didático das imagens dos azulejos, pelo menos durante as aulas. Contudo, não é de excluir que o Mestre usasse as cenas ou personagens representadas para ilustrar os temas abordados, mas teria de pedir aos alunos sentados e encostados aos painéis que se levantassem ou fossem sentar-se noutro lugar. Mas o ensino de ontem e de hoje não se resume à lição do Mestre e também neste caso havia outros momentos em que os alunos podiam contemplar e ler as máximas e nomes que constam dos painéis e que por volta de 1750 eram certamente um dos motivos de maior atração, pois ainda "cheiravam a fresco". Tais seriam o início da aula, enquanto aguardavam o mestre, o fim da aula, em que se levantavam, e outras ocasiões em que as salas fossem utilizadas.

O sentido de visualização das imagens dos azulejos que nos parece mais de acordo com a época é a partir da cátedra e no sentido dos ponteiros do relógio, da esquerda para a direita. É esta a disposição que vemos na sala 106, dedicada aos meses do ano e signos do zodíaco.

Devemos também integrar este recurso pedagógico no contexto geral dos colégios da Companhia. É conhecido o uso de decuriões, os alunos mais adiantados para dar algumas partes da matéria aos jovens estudantes (MONTEIRO, 2009, p. 72), estes alunos mais velhos teriam mais propensão a usar um método menos formal no ensino e assim recorrer às imagens dos azulejos. Vaz (2016, p. 169) descreve "uma paródia feita por quatro estudantes de Teologia aos Lusíadas", em 1589, que comprova essa propensão para um método menos formal e também para a divulgação das últimas novidades literárias na academia eborense. Por outro lado, era também frequente o recurso à representação dramática em épocas festivas e em diversas outras ocasiões, o que era um estímulo para utilizar as imagens dos painéis como modelos nessas representações, bem como outras inovações pedagógicas, como concursos literários (PATRÍCIO, 2012, p. 77; MONTEIRO, 2012, p. 222).

A decoração e a necessidade de proteção das paredes do edifício foram razões fundamentais para este projeto, mas isso não invalida que os mestres 
jesuítas tivessem também a intenção de dar às imagens um uso didático no sentido de reforçar com a imagem o ensino ministrado. Essa foi desde início uma diretriz da Companhia para o ensino da Matemática (LEITÃO, 2007a).

O que não duvidamos é que, no contexto do século XVIII, o revestimento das paredes das salas de aula, dos corredores e de outras dependências, foi um projeto de luxo e com uma visão de futuro no sentido de manutenção e higiene do edifício ${ }^{6}$. Não duvidamos também que continua a veicular, passados mais de 250 anos, uma mensagem pedagógica sobre temas diversificados, os quatro elementos, os continentes, as experiências físicas, os grandes filósofos da civilização ocidental e a ilustrar e dar a mensagem de obras imortais da cultura ocidental: a Bíblia, a Eneida e as Bucólicas de Virgílio.

Dado importante, que nos permite estabelecer uma relação dos painéis com o ensino, é o facto de em muitos casos as cenas representadas serem acompanhadas do texto em latim, como era de supor e dado que o ensino era nessa língua. Assim, o nome das personagens representadas, as máximas latinas descrevendo a cena, ou identificando a experiência e passagens das obras de autores, completam a informação necessária para o estudante - ou na atualidade o visitante, que agora tem à entrada da sala a explicação, em português e inglês, de cada cena representada nos painéis - identificar e compreender as imagens. Trata-se de uma novidade pedagógica que no contexto do século XVIII deve ser realçada e que nos faz olhar para os painéis como uma obra percursora da banda desenhada. Na verdade, se os benefícios da banda desenhada para o ensino passaram a ser valorizado no século XX e continuam a sê-lo na atualidade, sobretudo porque concilia a imagem com o texto, também os painéis do Colégio do Espirito Santo partem desse princípio e não é ousado dizer que contribuíram para abordar os conteúdos de forma mais simples e

\footnotetext{
${ }^{6}$ Pena é que muitos dos painéis apresentem já sinais de grande degradação, fruto do delir do tempo e do desleixo dos homens. Neste último aspeto, é de assinalar que as últimas grandes obras de recuperação dos azulejos do Colégio já datam de há mais de 50 anos e que à justa restauração e abertura da universidade em 1979 não se seguiu a justa e imprescindível restauração dos azulejos danificados. É obra urgente a necessitar da atenção dos dirigentes da instituição.
} 
motivadora.

Façamos uma viagem pelas salas onde esta conjugação da imagem e texto surge de forma bem vincada, para melhor compreender a relação com as matérias lecionadas. A descrição, ainda que breve dos painéis e texto, acompanhada com algumas imagens, permite-nos aferir melhor esta perspetiva pedagógica.

Quem ainda hoje entra na sala 118 e não tenha informação sobre a Eneida de Virgílio pode ficar com uma ideia das passagens marcantes dessa epopeia, incluindo a identificação das principais personagens. O herói Eneias está identificado, bem como o seu rival Turnus e o rei do Lácio, Latino e as suas filhas: Amata e Lavínia. Outras personagens centrais na obra estão também plasmadas nos azulejos: a deusa Vénus, a mítica figura de Troia e a lendária guerreira Camila. Ora o estudante de Latim e Retórica, que devia ler e reler a Eneida, tinha nesta sala aquilo que o manual não lhe oferecia: a imagem das personagens, a descrição das cenas principais, como o combate entre Eneias e Turnus, a visualização do horror, da violência e da crueldade da guerra; lá está representado um guerreiro a ser trespassado pela lança, outro jaz no chão já decepado, corpo para um lado e a cabeça para outro. A imagem ilustrava e completava as palavras magistrais do poema de Virgílio (Fig. 1).

Figura 1 - Cena da Eneida, sala 118.

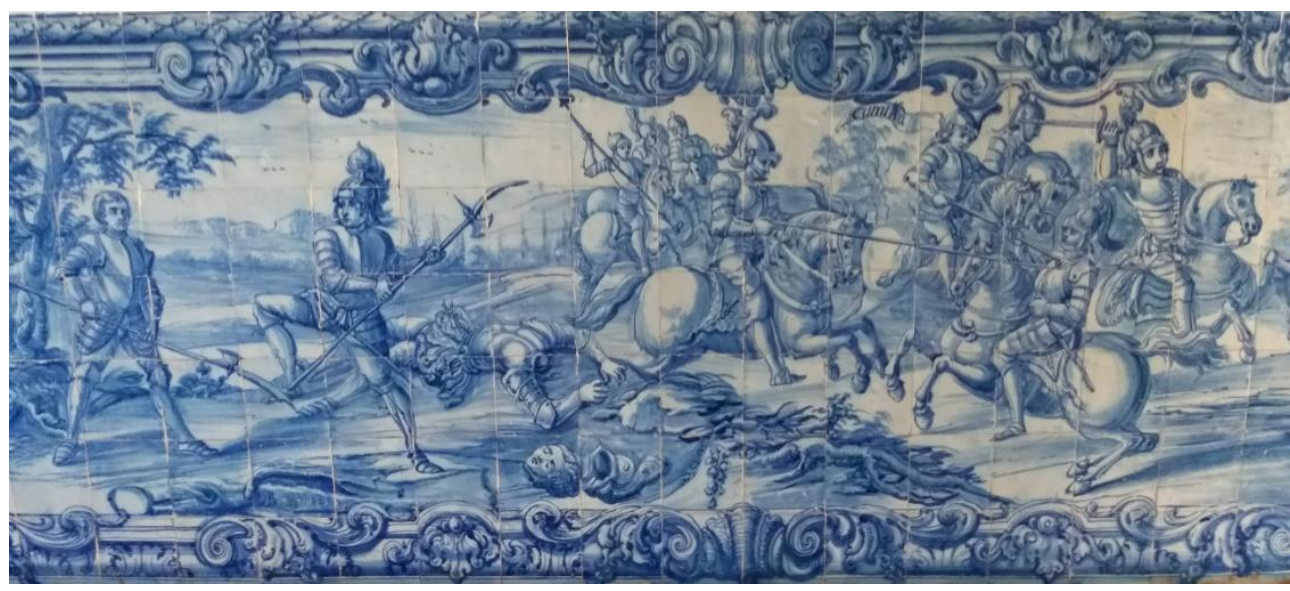

Fonte: fotografia de Francisco Vaz. 
Do mesmo modo, um ignorante de Filosofia clássica ao entrar na sala de Filosofia fica com a imagem e nome dos principais filósofos: Sócrates, Platão, Aristóteles, Zenão de Eleia, e até dos locais onde decorriam as preleções: a Academia de Platão, o Liceu de Aristóteles, ou ainda o nome do discípulo mais ilustre deste filósofo, com o painel "Aristóteles ensinando a Alexandre".

Com significado especial neste domínio da conjugação do texto com a imagem são as aulas dos Géneros Literários (107), a aula da Física (120) e a de Metafisica (121). Estas salas constituem bons exemplos das potencialidades pedagógicas, quer pela profusão de imagens, e pelo uso das legendas resumindo as experiências físicas, ou os géneros literários e suas características (Fig. 2).

Figura 2 - Experiência de Magdeburgo, sala 120.

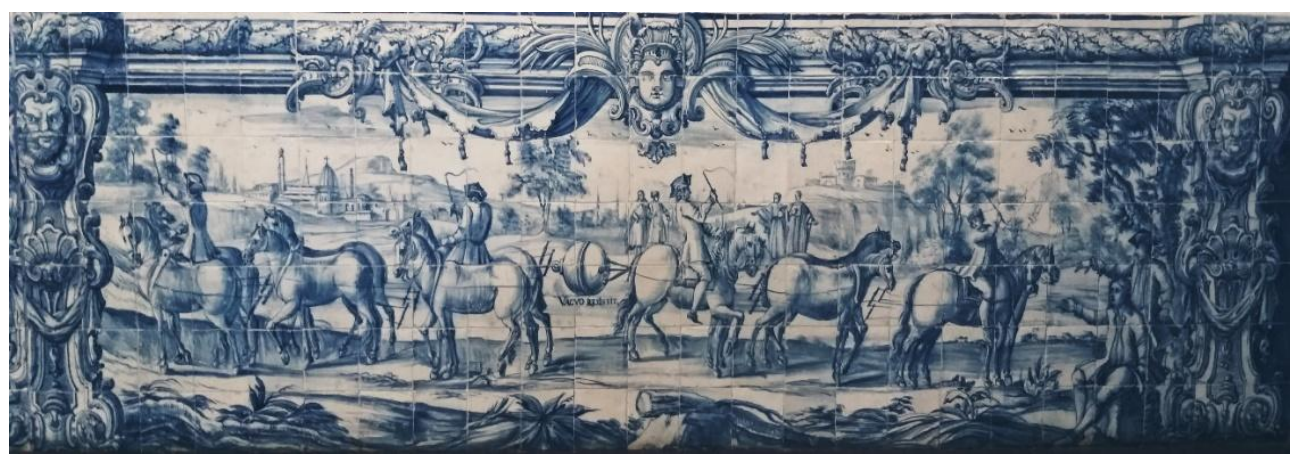

Fonte: fotografia de Francisco Vaz.

Mas, mesmo nas salas em que os painéis não têm texto, as imagens apresentam grandes potencialidades didáticas e pedagógicas. Assim, na sala 105, em sete painéis está representada a caça terrestre, homens a pé e a cavalo, auxiliados pelos cães perseguem as presas de caça grossa: veados, javali, lobo e avestruz. É possível apreender nas imagens o movimento, a rapidez do ataque, o trote e galope dos cavalos, e a ânsia dos cães pela presa. Do mesmo modo, está bem registrada a violência do ataque aos animais, cercados e trespassados pelas lanças e espadas. A visualização destas imagens proporciona uma autêntica lição sobre a arte venatória. 
Pode-se aferir e compreender os meios e técnicas da caça no século XVIII, bem como a desproporção de forças e meios utilizados; para caçar um veado, num dos painéis estão seis homens, dois a cavalo e quatro a pé, quatro cães e os dois cavalos, o que perfaz 12 criaturas para apanhar e matar um veado. E no painel da caça ao javali os caçadores perfazem 16: oito homens, seis a pé e dois a cavalo, seis cães, um dos quais com os dentes ferrados no pescoço do javali e, é claro, os dois cavalos. São imagens que ainda hoje nos mostram, de forma simples e direta, a violência e desumanidade que tem presidido na relação entre os homens e animais.

Outro aspeto que convém sublinhar - e que reforça a ideia destes painéis como percursores da banda desenhada - é o facto de apresentarem uma sequência, contarem uma história de caça de forma sequencial. Se visualizados da direita para a esquerda, o primeiro painel mostra a caça à avestruz, o segundo ao veado, o terceiro ao lobo, o quarto ao javali, o quinto e sexto de novo ao veado de diferentes tamanhos e no último painel é o final da caçada: caçadores e cavalos, transportando as presas, dirigem-se para a estalagem.

\section{OS AZULEJOS E A MISSIONAÇÃO}

O Colégio do Espirito Santo foi destinado pelos jesuítas ao ensino, desde o nível elementar até ao doutoramento em Teologia, e tendo em vista formar missionários para o país e ultramar. Foi com esta principal finalidade que a Companhia nasceu (MONTEIRO, 2012, p. 209). Os painéis de azulejos têm, ainda, uma leitura global que se relaciona com a formação de futuros missionários. De facto, os jovens deviam ter alguma informação sobre os usos, costumes, paisagens das terras que iam evangelizar, fosse na distante China, Japão, ou no Brasil, ou no Alentejo. Ora essa informação consta de alguns dos painéis, quer nas salas quer nas paredes do claustro do edifício. Assim, logo na entrada principal, a decoração com painéis de azulejos com imagens do Oriente, o que se designa de chinoserie, cumpre esse objetivo de dar uma informação, 
ainda que padronizada e rudimentar, sobre as gentes e paisagens dessas terras. Do mesmo modo, a representação dos quatro continentes na sala 122, fornece aos jovens estudantes uma ideia global sobre os cenários de cada continente, nomeadamente, sobre o exotismo, possibilitando, de forma direta, os traços caracterizadores dos destinos onde se vão criar as missões.

As imagens dos azulejos que os jovens viam e reviam nos dias de aulas eram como uma primeira viagem, com o auxílio da própria imaginação, às terras exóticas onde iriam exercer no futuro o seu apostolado em terras distantes da África, da Ásia e da América. Não abundando estampas ou figuras nos livros, os azulejos foram o meio para transmitir um conhecimento útil, para dar uma formação académica mais completa e assim cumprir a função pedagógica da Universidade.

\section{CONSIDERAÇÕES FINAIS}

A concretização do revestimento com painéis de azulejo, das salas de aula, corredores e outras dependências do Colégio do Espírito Santo, concluída por volta de 1749 , foi uma obra que viria a ser fundamental para a manutenção do edifício. Nunca é demais sublinhar este facto pelas repercussões que teve na conservação; vejam-se, entre outros aspetos que a cobertura com azulejos proporciona, a proteção contra a humidade, a limpeza e higiene das salas e corredores. Apresenta também, à semelhança de tantos outros edifícios com azulejo espalhados pelo país, um valor histórico e artístico fundamental: os azulejos estão no ambiente para que foram pensados, não se encontram fora do seu contexto e, por isso, têm ainda hoje valor de fontes primárias para a História em diversas componentes. Neste texto, centrámos a análise no seu valor enquanto meio didático e pedagógico.

Na continuidade de estudos anteriores, procurámos uma relação entre o ensino e as imagens representadas nos azulejos, partindo de um pressuposto, 
que consideramos fundamental no contexto do século XVIII: os manuais usados raramente apresentam imagens e as poucas que têm, à exceção das figuras geométricas do manual de Taquet, são estereotipadas e de tamanho reduzido. Bons exemplos são o manual da Física de António Mayer, sem qualquer figura, ou o de Retórica de Cipriano Soares, apenas com figuras reduzidas nas capitulares e que podemos interpretar como estereótipos; de febos, anjos e outras do género.

Deste modo e como vimos, com a adequação do espaço da aula a cada uma das disciplinas ministradas, as imagens dos azulejos completavam o que o mestre dizia e ilustravam os temas que os manuais expunham. Ora ontem como hoje uma imagem vale mais que mil palavras, seja para transmitir uma ideia seja para apelar à imaginação, isso mesmo terão compreendido os jesuítas, que recorreram a imagens nos diferentes níveis de ensino, desde o mais elementar, o ensino do catecismo, até ao universitário. Eram estas possibilidades que as imagens dos painéis de azulejo forneciam aos professores e aos jovens estudantes que seguiam as lições nas salas do Colégio do Espírito Santo. Do mesmo modo, as imagens dos painéis do Colégio na entrada e em algumas salas transmitiam aos jovens estudantes uma informação cosmopolita, ao retratarem usos e costumes das terras onde no futuro iam exercer o seu apostolado em África, Ásia, a América. Deste modo, os painéis de azulejos eram também um auxiliar didático e pedagógico para cumprir a principal finalidade da Companhia de Jesus: dar uma boa preparação a futuros missionários.

\section{REFERÊNCIAS}

ALVARES, Manuel. De Instructione Grammatica Libri tres. Èvora: Typographia Academia, 1689.

ARISTÓTELES. Parva Naturalia. Tradução: J. I. Beari e G.R.T Ross. 1955

Documenta Catholica Omnia. Disponível em: http://www.documentacatholicaomnia.eu/o3d/-384_322,_Aristoteles,_07_Parva_Naturalia,_EN.pdf. Acesso em: 6 dez. 2018. 
BÍBLIA SAGRADA. Lisboa: Difusora Bíblica, 1991.

BRANCO, Manuel Branco; SANTOS, João Santos. Colégio do Espírito Santo / Colégio da Companhia de Jesus / Universidade de Évora. In: Sistema de Informação para o Património Arquitectónico. Património Cultural, Direção-Geral do Património Cultural, 2005. Disponível em: http://www.monumentos.gov.pt/Site/APP_PagesUser/SIPA.aspx?id=3839. Acesso em: 9 mar. 2019.

CARDOSO, Simão. A Gramatica Latina no século XVI. Revista da Faculdade de Letras "Línguas e Literaturas", Porto, XII, p. 159-172. Disponível em: http://ler.letras.up.pt/uploads/ficheiros/2703.pdf. Acesso em 28 set. 2018.

CARVALHO, Rómulo de. História do ensino em Portugal. Lisboa: Fundação Calouste Gulbenkian, 2008.

CONDE, Antónia Fialho; RODRIGUES, Paulo Simões; SOARES, João. Os Colégios da Universidade de Évora: recriação, evocação e capricho. In: PEREIRA, Sara Marques; VAZ, Francisco Lourenço (coord.). Universidade de Évora: 450 anos de modernidade educativa. Lisboa: Chiado, 2012. p. 447-472.

FONSECA, Fernando Taveira. A Universidade de Évora (1559-1759): história e historiografía. In: RODRÍGUEZ-SAN PEDRO BEZARES, Luis; POLO RODRÍGUEZ, Juan Luis (ed.). Salamanca y su universidad en el primer Renacimiento: siglo XV. 1. ed. Salamanca: Ediciones Universidad de Salamanca, 2011 (Miscelánea Alfonso IX). p. 385-418.

GOMES, João Pereira. Os professores de Filosofia da Universidade de Évora (1559-1759). Évora: Câmara Municipal, 1960.

LEITÃO, Henrique. A Ciência na aula da esfera do Colégio de Santo Antão, 1590-1759. Lisboa: Comissariado Geral das Comemorações do V Centenário do Nascimento de S. Francisco Xavier, 2007b.

LEITÃO, Henrique. Azulejos que testemunham uma tradição de ensino científico: exposição azulejos que ensinam. Coimbra: Centro de Matemática da Universidade de Coimbra, 2007a. Disponível em:

https://www.academia.edu/35833847/Azulejos_que_testemunham_uma_trad i\%C3\%A7\%C3\%A30_de_ensino_cient\%C3\%ADfico. Acesso em: 9 mar. 2019.

LEITÃO, Henrique. Jesuit Mathematical Practice in Portugal, 1540-1759. In: FEINGOLD, Mordechai (ed.). The new science and jesuit science: seventeenth century perspectives. Dordrecht: Kluwer Academic Publishers, 2003. p. 229-247. 
LOBO, Rui. O Colégio-Universidade do Espírito Santo de Évora. Évora: Centro de História da Arte e Investigação Artística da Universidade de Évora, 2009.

MARONIS, Publio Virgílio. Eneida. Tradução: Manuel Odorico Mendes. Ebooks Brasil, 2005. Disponível em:

http://www.ebooksbrasil.org/eLibris/eneida.html. Acesso em: 25 mar. 2019.

MAYER, Antonio. Philosophia peripatetica: antiquorum principiis et recentiorum experimentis, Tomo Secundus, Physica Universalis. Veneza: Nicolau Pezzana, 1745.

MAYER, Antonio Mayr. Philosophia peripatetica: antiquorum principiis et recentiorum experimentis conformata, Tomus Primus, Logica. Veneza:

Nicolaum Pezzana, 1745 .

MENDEIROS, José Filipe. Os azulejos na Universidade de Évora $=$ The tiles of the University of Évora. Évora: Universidade de Évora, 2002.

MIRANDA, Margarida. Quando os jesuítas eram mestres da palavra: a retórica segundo a ratio studiorum. Humanitas, v. 65, p. 180-202, 2013. Disponível em: https://digitalis.uc.pt/pt-

pt/artigo/quando_os_jesu\%C3\%ADtas_eram_mestres_da_palavra_ret\% $3 \% \mathrm{~B}$ 3rica_segundo_ratio_studiorum. Acesso em: 10 mar. 2019.

MONTEIRO, Miguel. A fundação de Colégios e o esforço missionário dos jesuítas. In: PEREIRA, Sara Marques; VAZ, Francisco (coord.). Universidade de Évora: 450 anos de modernidade educativa. Lisboa: Chiado, 2012. p. 209225 .

MONTEIRO, Miguel. Características educativas inacianas. Algumas reflexões. Revue, Évora, Universidade de Évora, n. 10-11, p. 62-77, 2009.

PATRÍCIO, Manuel Ferreira, Em torno das figuras maiores da primeira Universidade de Évora. In: PEREIRA, Sara Marques; VAZ, Francisco (coord.). Universidade de Évora: 450 anos de modernidade educativa. Lisboa: Chiado, 2012. p. 71-80.

PEREIRA, Maria Helena Rocha. Evocação do Congresso comemorativo da inauguração da Universidade de Évora. In: PEREIRA, Sara Marques; VAZ, Francisco (coord.). Universidade de Évora: 450 anos de modernidade educativa. Lisboa: Chiado, 2012. p. 653-659.

POLÓNIA, Amélia. A fundação da Universidade de Évora. Em análise contextual. A universidade ao serviço de um projeto pastoral e pedagógico. In: 
PEREIRA, Sara Marques; VAZ, Francisco (coord.). Universidade de Évora: 450 anos de modernidade educativa. Lisboa: Chiado, 2012. p. 81-100.

RODRIGUES, Francisco. História da Companhia de Jesus na Assistência a Portugal. t. I. Porto: Liv. Apostolado, 1931.

RUEGG, Walter (coord.). Uma história da universidade na Europa. As universidades na Europa Moderna (1500-1800). v. 2. Lisboa: Imprensa Nacional-Casa da Moeda, 2002.

SIMÕES, João Miguel dos Santos. Azulejaria em Portugal no século XVII. Lisboa: Fundação Calouste Gulbenkian, 1971 (2 vols.).

SIMÕES, João Miguel dos Santos. Azulejaria em Portugal no século XVIII. Lisboa: Fundação Calouste Gulbenkian, 1997.

SIMÕES, João Miguel dos Santos. Azulejaria em Portugal nos séculos XV e XVI: introdução geral. Lisboa: Fundação Calouste Gulbenkian, 1990.

SUAREZ, Cipriano. De arte rhetorica libri tres ex Aristotele, Cicerone \& Quintiliano. Coimbra: Ioannem Barrerium, 1562.

TACQUET, Andrea. Elementa Geometriae Planae e Solidae. Antuerpia: Jacobo Mersium , 1672.

TOBIAS, Werner. Os azulejos na Universidade de Évora: um contributo para a conceção das ciências e para a didáctica académica no século XVIII. Osnabruck: Universitat Osnabruck, 1987.

VAZ, Francisco. A cidade de Évora na vida e obra de Bento Farinha. Boletim da Câmara Municipal de Évora. Évora: Câmara Municipal, ${ }^{a}$ serie, n. 2, 1996-1997, p. 447-492.

VAZ, Francisco. O ensino dos jesuítas na Universidade de Évora - Uma leitura dos primeiros estatutos. História da Educação, Porto Alegre, v. 20, n. 48, p. 159-174, jan./abr. 2016. Disponível em:

https://seer.ufrgs.br/asphe/article/view/54306. Acesso em: 28 maio 2019.

VAZ, Francisco. Os jesuítas e o ensino do catecismo - a doutrina cristã do P. Marcos Jorge e de Mestre Inácio. Revista Teoria e Prática da Educação, v. 20, n. 1, p. 23-34, jan./abr. 2017.

VAZ, Francisco; PEREIRA. Sara Marques. Antologia de textos da Universidade de Évora. Lisboa: Chiado, 2012. 
FRANCISCO ANTÓNIO LOURENÇO VAZ é professor do Departamento de História - Escola de Ciências Sociais. Investigador do CIDEHUS (Centro Interdisciplinar de História, Culturas e Sociedades) - Universidade de Évora. É Licenciado em História pela Universidade do Porto, Mestre em História Cultural e Política pela Universidade Nova de Lisboa, Doutor em História da Cultura Moderna e Contemporânea, pela Universidade de Évora.

E-mail: fvaz@uevora.pt

(1) http://orcid.org/0000-0002-6154-4218

Recebido em: 03 de junho de 2019

Aprovado em: 14 de fevereiro de 2020

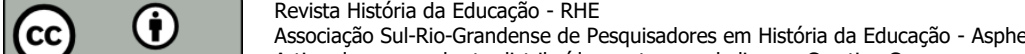
Artigo de acesso aberto distribuído nos termos de licença Creative Commons.
} 